\title{
Posttraining Sleep Enhances Automaticity in Perceptual Discrimination
}

\section{Citation}

Atienza, Mercedes, Jose L. Cantero, and Robert Stickgold. 2004. “Posttraining Sleep Enhances Automaticity in Perceptual Discrimination." Journal of Cognitive Neuroscience 16 (1): 53-64. doi:10.1162/089892904322755557.

\section{Permanent link}

http://nrs.harvard.edu/urn-3:HUL.InstRepos:41543092

\section{Terms of Use}

This article was downloaded from Harvard University's DASH repository, and is made available under the terms and conditions applicable to Other Posted Material, as set forth at http:// nrs.harvard.edu/urn-3:HUL.InstRepos:dash.current.terms-of-use\#LAA

\section{Share Your Story}

The Harvard community has made this article openly available.

Please share how this access benefits you. Submit a story.

Accessibility 


\title{
Posttraining Sleep Enhances Automaticity in Perceptual Discrimination
}

\author{
Mercedes Atienza $^{1}$, Jose L. Cantero ${ }^{1}$, and Robert Stickgold ${ }^{2}$
}

\begin{abstract}
Perceptual learning can develop over extended periods, with slow, at times sleep-dependent, improvement seen several days after training. As a result, performance can become more automatic, that is, less dependent on voluntary attention. This study investigates whether the brain correlates of this enhancement of automaticity are sleep-dependent. Event-related potentials produced in response to complex auditory stimuli were recorded while subjects' attention was focused elsewhere. We report here that following training on an auditory discrimination task, performance continued to improve, without significant further training, for $72 \mathrm{hr}$. At the same time,
\end{abstract}

\section{INTRODUCTION}

A key unresolved issue in neuroscience is how, where, and when long-term memories are encoded in the brain. It is broadly accepted that the establishment of longterm memory requires a complex cascade of neural events at molecular, cellular, and network levels that occurs over different time scales. However, relatively little is known about the time course and state dependency of the slowest of these events.

Growing evidence supports a role for sleep in memory consolidation, particularly in the consolidation of perceptual and motor learning (Maquet, 2001; Stickgold, Hobson, Fosse, \& Fosse, 2001). Immediate gains in performance on procedural tasks have been hypothesized to stem from alterations in cortical dynamics involving rapid changes in the tuning of neurons within primary sensorimotor cortex during the training period with concomitant changes in the properties of neuronal receptive fields (Gilbert, 1994; Kapadia, Gilbert, \& Westheimer, 1994). These are followed by slower changes that evolve with no additional training over the following hours or days and that are believed to include enlargement of the cortical areas representing the learned information (Karni, Weisberg, Lalonde, \& Ungerleider, 1995; Recanzone, Merzenich, Jenkins, Grajski, \& Dinse, 1992; Recanzone, Schreiner, \& Merzenich, 1993), changes in the temporal organization of neuronal re-

${ }^{1}$ University Pablo de Olavide, Spain, ${ }^{2}$ Harvard Medical School several event-related potential components became evident 48$72 \mathrm{hr}$ after training. Posttraining sleep deprivation prevented neither the continued performance improvement nor the slow development of cortical dynamics related to an enhanced familiarity with the task. However, those brain responses associated with the automatic shift of attention to unexpected stimuli failed to develop. Thus, in this auditory learning paradigm, posttraining sleep appears to reduce the voluntary attentional effort required for successful perceptual discrimination by facilitating the intrusion of a potentially meaningful stimulus into one's focus of attention for further evaluation. sponses (Recanzone et al., 1992, 1993), variations in the excitatory/inhibitory patterns of intracortical connections (Crist, Li, \& Gilbert, 2001; Jacobs \& Donoghue, 1991), and/or a shift in the locus of representation from higher to lower areas of sensory processing, suggesting alterations in the brain mechanisms mediating attentional control (Vaina, Belliveau, des Roziers, \& Zeffiro, 1998; Shadmehr \& Holcomb, 1997).

Previous studies have shown that such slow neural changes, responsible for the stabilization of information, strengthening of memories, and automatization of tasks might be promoted during diurnal (Mednick et al., 2002) and nocturnal sleep (Fenn, Nussbaum, \& Margoliash, 2003; Walker et al., 2003, 2002; Fischer, Hallschmid, Elsner, \& Born, 2002; Gais, Plihal, Wagner, \& Born, 2000; Maquet et al., 2000; Stickgold, James, \& Hobson, 2000; Stickgold, Whidbee, Schirmer, Patel, \& Hobson, 2000; Karni et al., 1994; Smith \& MacNeill, 1994). Posttraining sleep seems to be important for improvement to occur in the absence of additional practice. For instance, subjects deprived of sleep the night after training failed to improve on a visual texture discrimination task even after two nights of recovery sleep (Stickgold, James, et al., 2000). Similarly, subjects trained on a short sequence of finger movements showed a $20 \%$ increase in speed, without loss of accuracy, over a night of sleep but not over a similar period of daytime wakefulness (Walker et al., 2002) and not across a night without sleep (Fischer et al., 2002).

Changes in cortical dynamics after perceptual training have been studied in the intact human brain by mea- 
suring variations in event-related brain potentials (ERPs) and their magnetic counterparts (Atienza, Cantero, \& Dominguez-Marin, 2002a; Song, Ding, Fan, \& Chen, 2002; Tervaniemi, Rytkönen, Schröger, Ilmoniemi, \& Näätänen, 2001; Menning, Roberts, \& Pantev, 2000; Tremblay, Kraus, \& McGee, 1998; Tremblay, Kraus, McGee, Ponton, \& Otis, 2001; Kraus et al., 1995, 1996; Näätänen, Schröger, Karakas, Tervaniemi, \& Paavilainen, 1993; Pascual-Leone \& Torres, 1993). At the cellular level, ERPs reflect changes in electric (or magnetic) field potentials, mainly resulting from transmembrane currents in neuronal dendrites during synaptic activity (Humphrey, 1968). Since learned information is represented in the nervous system by the coordinated activity of neuronal ensembles (Gilbert, Sigman, \& Crist, 2001), perceptual learning should be reflected in modulations of the stimulus-driven ERP.

In the present study, two temporal phases were identified following training on an auditory discrimination task. The first occurs during training and is seen both as improved performance and changes in the ERPs. The second phase occurs much later and is seen in further behavioral improvement and ERP modulations that only become apparent $48 \mathrm{hr}$ after training. Three distinct ERP changes linked to different stages of processing are evident at $48 \mathrm{hr}$. One of these, related to an enhanced familiarity with the task, is resistant to posttraining sleep deprivation, while the other two, which facilitate the involuntary shifting of attention, fail to develop after such deprivation.

\section{RESULTS}

\section{Rapid and Delayed Behavioral Improvement}

Twenty subjects were trained in a single session to discriminate two complex auditory patterns, identical except for a $15 \%$ increase in the frequency of the sixth of eight component tones (see Methods). Participants were at chance levels ( $\sim 13 \%$ accuracy) detecting the deviant stimulus during the first blocks of training and only reached criterion (80\% accuracy with minimal false alarms) after $6-13$ blocks. Ten of these subjects were deprived of sleep on the first night after training, while the remaining 10 control subjects slept at home. Both groups were retested with single blocks of trials at 48 and $72 \mathrm{hr}$ after training.

As shown in Figure 1 (top panel), both groups were more accurate with the passage of time $[F(2,34)=11.4$, $p<.001, \varepsilon=.96$, two-way analysis of variance (ANOVA) with group as between factor and session as within factor]. Accuracy (as revealed by the $d^{\prime}$ index) increased from training to 48 and $72 \mathrm{hr}(p<.01$, Newman-Keuls), but no significant increase was seen from 48 to $72 \mathrm{hr}$. Similarly, control and sleep-deprived subjects were faster $[F(2,34)=14.3, p<.0001, \varepsilon=.97$, two-way ANOVA $]$ in retest sessions (Figure 1, bottom panel), reaction times (RT) showing a continued increase in speed not only from training to $48 \mathrm{hr}$, but from 48 to $72 \mathrm{hr}(p<.02$, Newman-Keuls) as well. No performance differences were seen between the two groups in speed or accuracy.

\section{Rapid Changes in Cortical Dynamics}

ERPs to standard and deviant auditory patterns were recorded in both experimental and control subjects just before and after training, as well as before retests of performance at 48 and $72 \mathrm{hr}$. When measured prior to training, ERPs in response to the standard and deviant tones were indistinguishable (Figure 2, pretraining), but differences in the processing of the two auditory patterns became evident for both groups immediately after training (Figure 2, posttraining, solid fill). A significant negative (upward) waveform was seen in the ERPs elicited by the deviant pattern, after subtracting ERPs elicited by the standard pattern, for both the control and sleep-deprived group (Figure 3). This deviance-related negativity, peaking 150-200 msec after the start of the deviant tone (vertical dashed line, $225 \mathrm{msec}$ after stimulus onset),

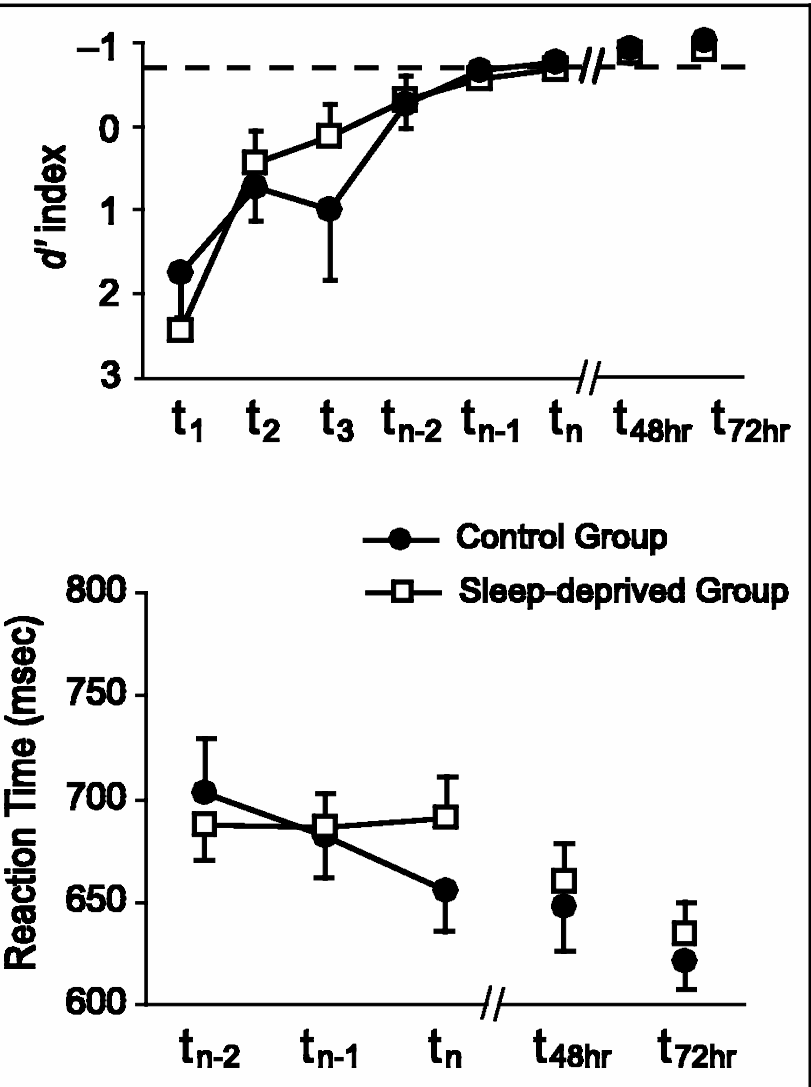

Figure 1. Behavioral results across time for the control and sleep-deprived group. Top: Accuracy in the auditory discrimination task as revealed by the detection index $d^{\prime}$ is shown for the first three and last three blocks of training as well as for the retest sessions. The dashed horizontal line denotes the threshold $d^{\prime}$ value required to end the training session. Bottom: Mean RT is shown for the three last blocks within the training session and for each retest session. Error bars indicate $S E M$. 


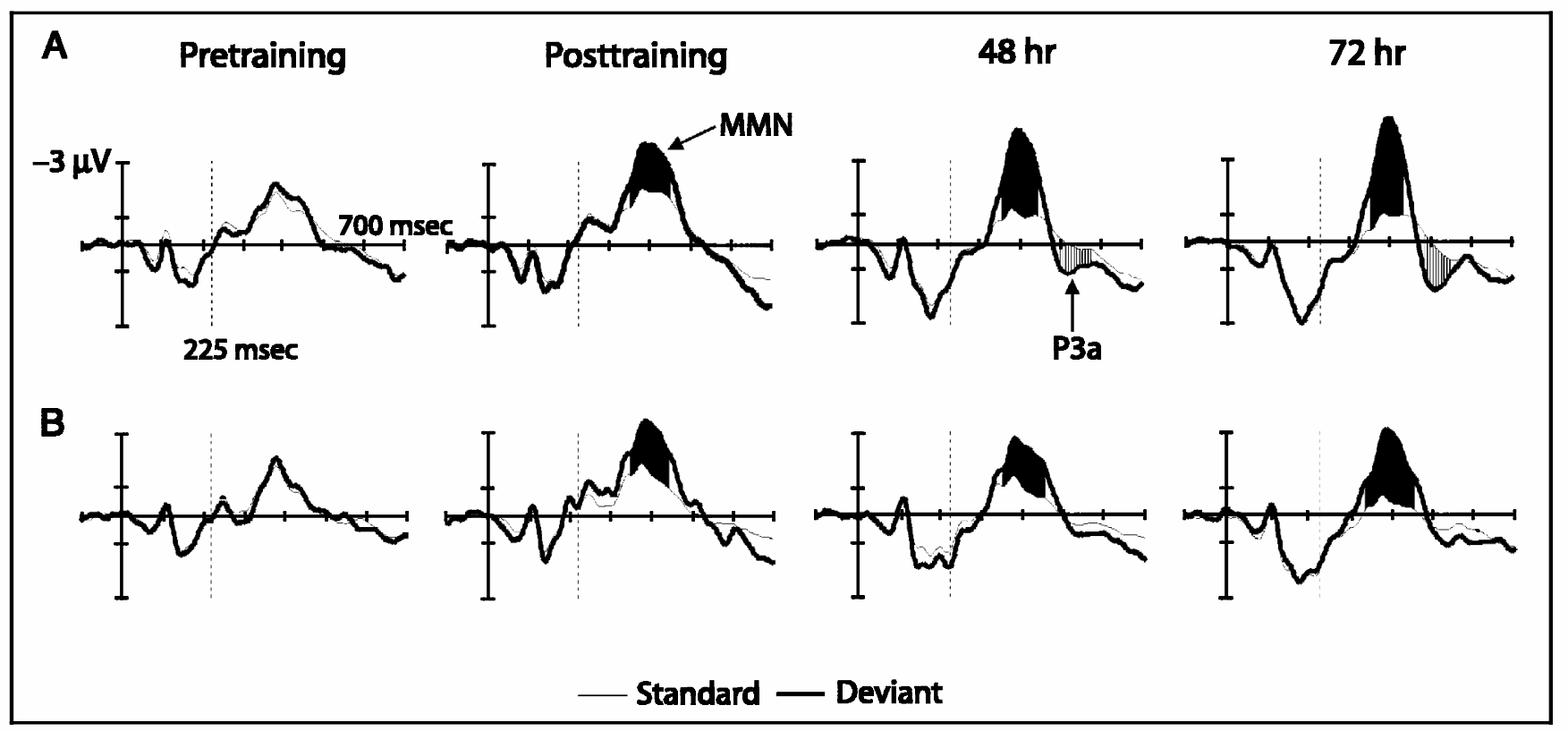

Figure 2. Brain ERPs to the standard and deviant auditory pattern across time. Averaged event-related response recorded at Fz to the standard and deviant pattern immediately before and after training as well as at 48 and $72 \mathrm{hr}$ posttraining are shown for the control (A) and sleep-deprived groups (B). The filled areas denote time periods with significant differences $(p<.001)$ between the two patterns (paired $t$ tests performed for 20-msec windows starting from the introduction of the sixth deviant tone denoted by the vertical dashed line). Solid fill: MMN wave; hatched fill: P3a wave.

showed maximum amplitude over fronto-central regions of the scalp and inverted polarity at mastoid electrodes (see Fz and R3 in Figure 3, pre- and posttraining conditions), suggesting a generator source in the vicinity of auditory cortex (Scherg, Vajsar, \& Picton, 1989). Both the latency and topographic distribution correspond to the "mismatch negativity" (MMN), a brain component of ERPs developing mainly in the auditory cortex in response to infrequent changes in previously registered regularities in acoustic sequences, even in the absence of attention (Näätänen, Tervaniemi, Sussman, Paavilainen, \& Winkler, 2001).

\section{Slow Changes in Cortical Dynamics}

As expected from the behavioral results, changes in the neural processing of the sound patterns, reflected in ERP recordings, continued to develop slowly after training without further rehearsal. One such change was a further increase in MMN amplitude at frontal derivations, but not at mastoid electrodes, seen in the control group 48 and 72 hr posttraining $(p<.0001$, ANOVA Group $\times$ Session interaction and Newman-Keuls for the control group; see Figure 3, 48 and $72 \mathrm{hr}$ ). Subjects in the sleep-deprived group showed no such increase at $48 \mathrm{hr}$, and while they did show a small increase in MMN amplitude $72 \mathrm{hr}$ posttraining, it did not reach statistical significance. In fact, the MMN amplitude in the sleep-deprived group was significantly smaller at both 48 and $72 \mathrm{hr}$ than in the control group at $48 \mathrm{hr}$ ( $p=.05, t$ tests).

A second change in the neural processing of the sound patterns was reflected approximately $300 \mathrm{msec}$ after the start of the deviant tone (Figure 2, hatched area). These distinctions can be identified in the difference wave as a small positive (downward) potential, with maximum amplitude over frontal regions, corresponding to the $\mathrm{P} 3 \mathrm{a}$ (Figure 3, 48 and $72 \mathrm{hr}$ ). This wave is known to reflect the involuntary switch of attention to environmental novel stimuli (Escera, Alho, Schröger, \& Winkler, 2000; Alho, Escera, Díaz, Yago, \& Serra, 1997) and has been reported for relatively small deviancies in physical parameters of a sound sequence when the primary task is not very demanding (Baudena, Halgren, Heit, \& Clarke, 1995; Picton, 1992; Sams, Paavilainen, Alho, \& Näätänen, 1985). As with the increase in MMN amplitude, the P3a wave was only seen after 48 and $72 \mathrm{hr}$ and only in the control group, not in the sleepdeprived group.

A third slowly developing change was observed in the early portion of the ERP, for both the standard and deviant pattern and appearing before the presentation of the potentially deviant, sixth tone. This slow positive wave (SPW) appeared 180-260 msec after stimulus onset, superimposed on the P2 component of the ERP, although the SPW lasted considerably longer than the standard P2. The SPW only became evident $48 \mathrm{hr}$ after training, but, unlike the MMN and P3a responses, was seen in both the control and sleep-deprived groups. The SPW could be more readily seen in the difference wave obtained after subtraction of the pretraining ERP (Figure 4). ANOVAs including session (pretraining, posttraining, $48 \mathrm{hr}$ posttraining, and $72 \mathrm{hr}$ posttraining) as the within factor and group (control and sleep-deprived) as the between factor were performed within 20-msec 


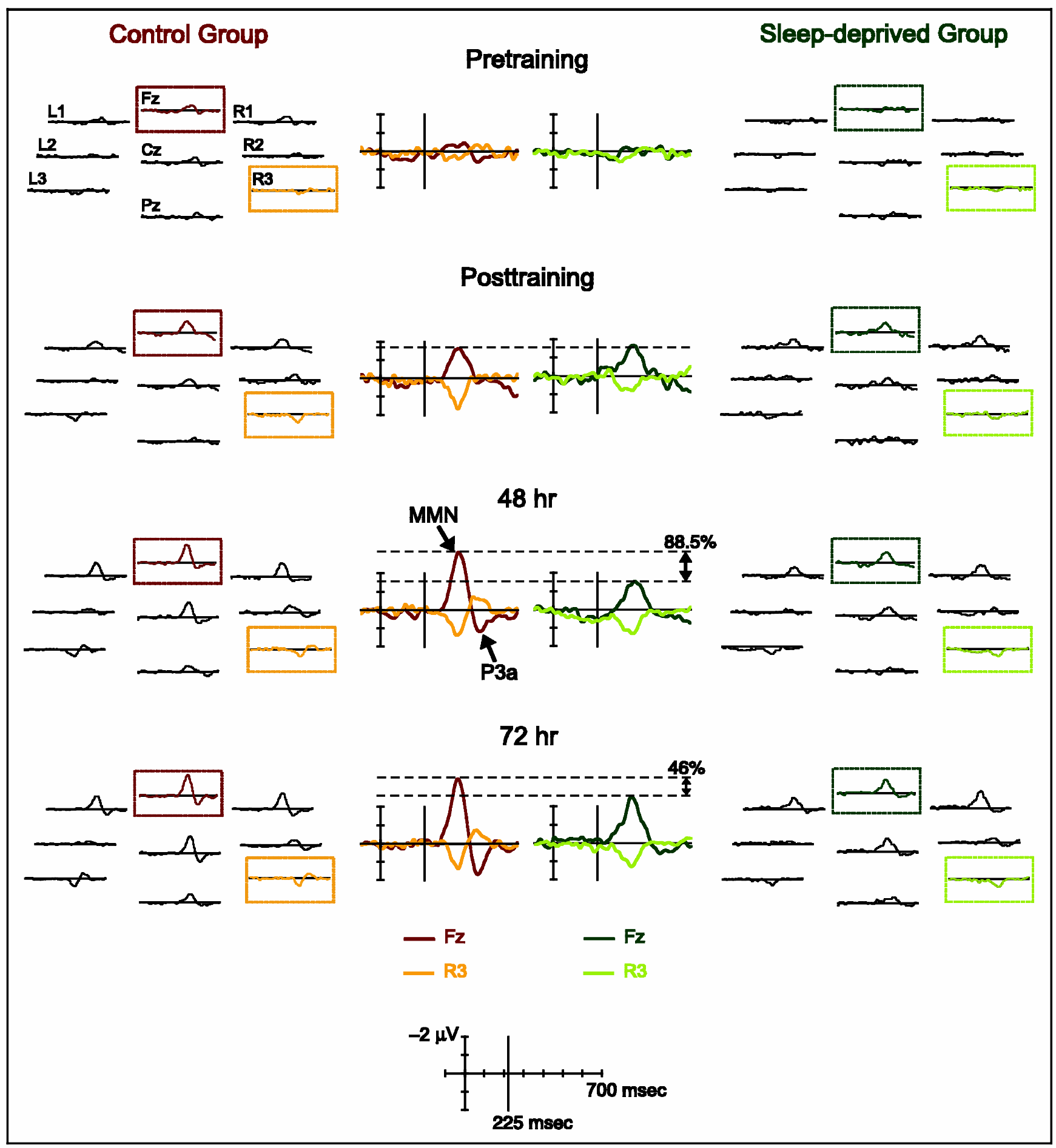

Figure 3. Grand average difference waves in the control (red) and sleep-deprived (green) groups across test sessions. Enlargements of the difference waves at Fz and R3 (right mastoid) for each group (control group on the left and sleep-deprived group on the right) are shown in the middle column. Horizontal dashed lines represent peak amplitudes of MMN at Fz; percent increases in peak amplitudes for control group are indicated. Top to bottom: Immediately before training, immediately after training, $48 \mathrm{hr}$ posttraining, and $72 \mathrm{hr}$ posttraining.

windows from 160 to $300 \mathrm{msec}$ after stimulus onset. The SPW was larger at 48 and $72 \mathrm{hr}$ as compared with pre- and posttraining sessions between 180 and $260 \mathrm{msec}$ from stimulus onset $(p<.0001$, Newman-Keuls). However, no difference between groups or no interaction effect was found in any temporal window. The SPW was maximal over frontal areas, and, like the MMN and $\mathrm{P} 3 \mathrm{a}$, reversed polarity at the mastoid electrodes, suggesting that the brain generator for this wave was also located in auditory cortex.

Since the SPW was seen equally for standard and deviant sound patterns, it most likely results from a 


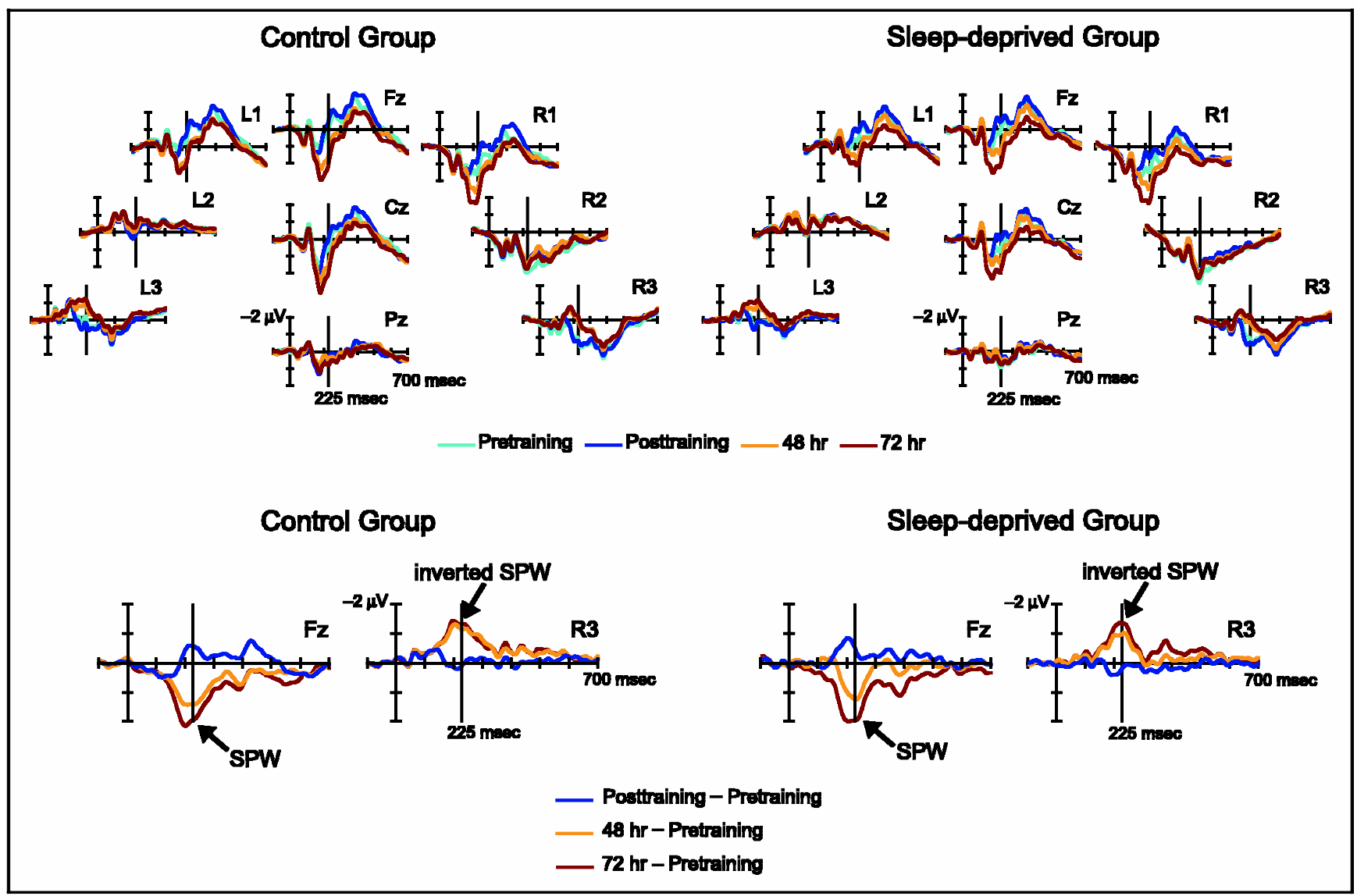

Figure 4. Superimposed brain responses to the standard pattern recorded at all derivations in the control and sleep-deprived group immediately before and after training as well as at 48 and $72 \mathrm{hr}$ posttraining. Top: Grand average ERPs for control and sleep-deprived subjects. Bottom: Grand average difference waves (relative to pretraining) at frontal (Fz) and mastoid (R3) electrodes for control and sleep-deprived subjects.

general experience-dependent enhancement of sound pattern processing, possibly reflecting greater familiarity with the sound patterns, as discussed below.

\section{DISCUSSION}

Training on an auditory discrimination task led to three distinct changes in the auditory ERP (Figure 5)—one of them (MMN) already evident immediately after training and the remaining two (SPW and P3a) evolving over the next 2-3 days in parallel with further behavioral improvement. These slower cortical changes were differentially affected by sleep deprivation (see schematic description in Table 1). While cortical changes seen equally in response to standard and deviant sound patterns (SPW) were unaffected by sleep deprivation, changes in cortical dynamics directly related to the deviant sound pattern (MMN and P3a) appeared to require sleep on the first night after training. Unexpectedly, there was no evidence of performance differences between the control and sleep-deprived groups. Thus, the continued slow (sleep-independent) improvement in task performance does not appear to correlate with the slow (sleep-dependent) enhancement in the MMN and P3a. Rather than being involved in the enhancement of performance under conditions of focused attention, we propose that these sleep-dependent changes in cortical dynamics are directly related to the automatic detection of unattended sounds.

\section{Mismatch Negativity and P3a}

Of the three ERP changes, only the MMN was evident immediately after completion of the training session (i.e., practice-dependent). The MMN wave is thought to reflect an automatic comparison process between a stored cortical representation of an immediately preceding auditory sequence and an incoming stimulus (Näätänen \& Winkler, 1999). This notion is supported by the fact that the MMN is elicited automatically, regardless of the focus of attention, to deviant sounds embedded within a repetitive sound sequence. If the repetitive (i.e., standard) sound is removed from that sequence, no MMN is elicited (King, McGee, Rubel, Nicol, \& Kraus, 1995). The strongest evidence for its automaticity comes from several studies reporting MMN elicitation during sleep (e.g., Nashida et al., 2000; Atienza, Cantero, \& Gómez, 1997, 2000; Loewy, Campbell, \& Bastien, 1996; for recent reviews, 
see Atienza, Cantero, \& Dominguez-Marin, 2002b; Atienza, Cantero, \& Escera, 2001).

Two different brain mechanisms seem to be involved in generation of the MMN, one localized bilaterally in the auditory cortex (Halgren, Baudena, Clarke, Heit, Liegogis, et al., 1995; Halgren, Baudena, Clarke, Heit, Marinkovic, et al., 1995), especially in association areas (Kropotov et al., 2000; Alain, Woods, \& Knight, 1998), and the other in frontal regions of the right hemisphere
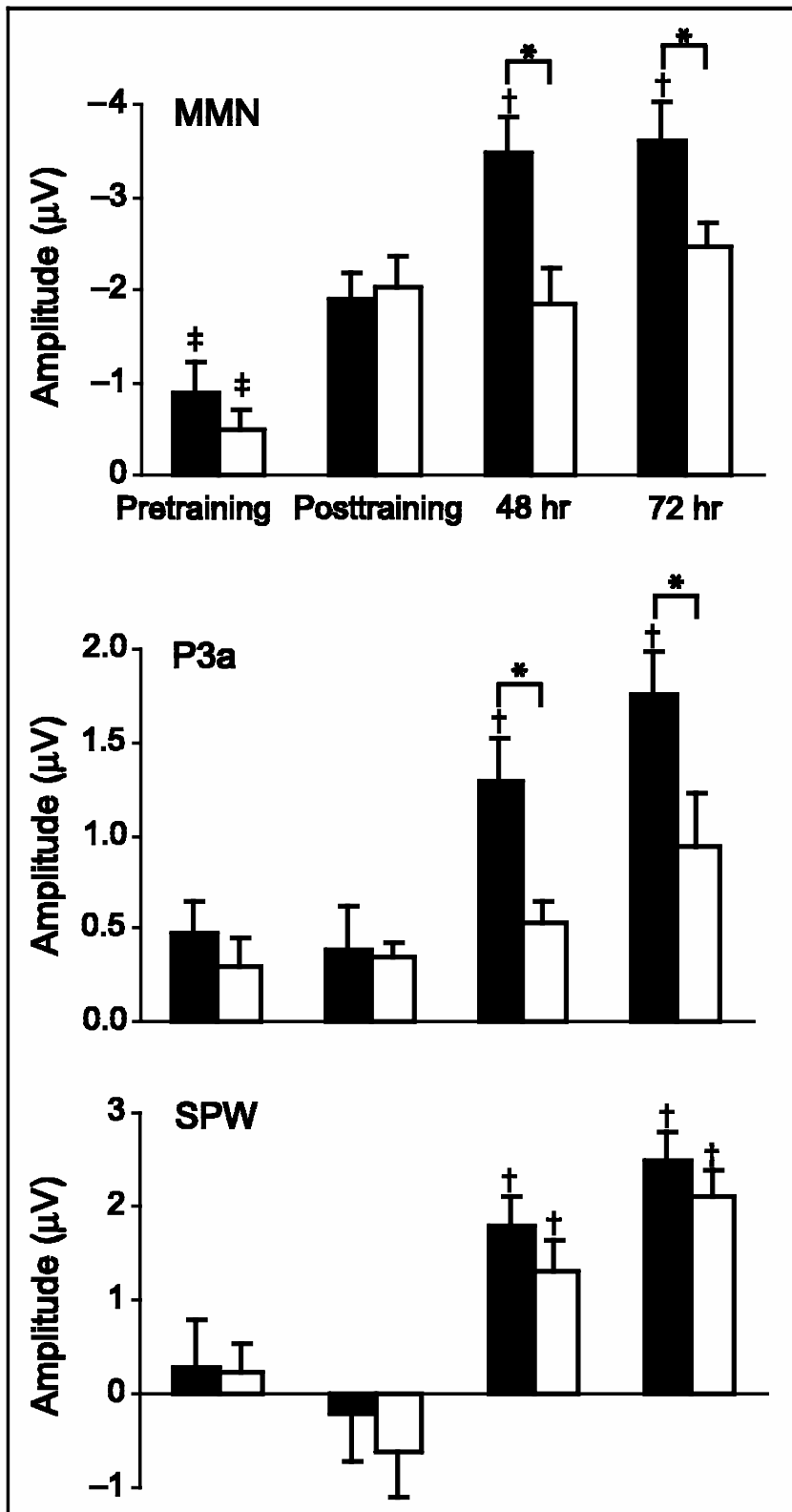

Control Group

\section{Sleep-deprived Group}

Figure 5. Time course of the cortical changes across sessions. Top: MMN amplitude; middle: P3a amplitude; bottom: SPW amplitude from group grand averages. Error bars $=S E M$. *Significant difference between groups $(p<.05)$. ${ }^{\dagger}$ Significantly greater than at posttraining test $(p<.05)$. ${ }^{\ddagger}$ Significantly less than at posttraining tests $(p<.05)$.
(Opitz, Rinne, Mecklinger, von Cramon, \& Schröger, 2002). The temporal cortex component (identified in the present study by its phase reversal at mastoid electrodes) is mainly involved in stimulus-driven change-detection processes that are based on extraction of repetitive aspects of a sound sequence (Näätänen \& Winkler, 1999). This is the principal component responsible of the increased MMN observed immediately after training.

In contrast, the frontal component of the MMN is thought to reflect the triggering of an automatic shift of attention toward the deviant stimulus (Näätänen, 1992), which is indexed by the subsequent P3a wave (Escera et al., 2000). The output of this triggering system most likely signals that the neural activity generated by the unattended event has exceeded some threshold (Näätänen, 1990), thereby interfering with frontal inhibitory mechanisms that appear to maintain voluntary attentional focus (McDowd, 1997; Kramer, Humphrey, Larish, Logan, \& Strayer, 1994). Thus, the emergence of the P3a component at $48 \mathrm{hr}$, after the MMN showed an additional significant increase in amplitude, suggests that the increased neural excitability only then exceeded some threshold level, leading to a shift of attention to the previously unattended event.

Unfortunately, ERP measurements cannot fully resolve the two components of the MMN. Nevertheless, the absence of a P3a wave immediately after training suggests that the MMN seen at the end of training is due primarily to its auditory cortex component, while its subsequent enlargement over frontal regions may receive an important contribution from the frontal component. Strikingly, this second, frontal component was only evident, together with the P3a, in subjects who were allowed to sleep the night after training.

The ability of the auditory cortex to detect deviant sound patterns improves over the course of training, and likely contributes to the improved performance seen with training. But the ability of the MMN system to trigger, presumably via frontal lobe mechanisms, an automatic shift of attention to the deviant pattern, develops more slowly and in a sleep-dependent manner. In a previous study (Atienza et al., 2002a), subjects were trained on the same task and tested for both behavioral and ERP changes every $12 \mathrm{hr}$ for a period of $48 \mathrm{hr}$. As in the present study, the MMN was first observed at the completion of training. No further improvement in performance and no additional enhancement in the MMN were seen until $36 \mathrm{hr}$ after training, when the MMN increase was again limited to fronto-central derivations. Only at $48 \mathrm{hr}$ was a small $\mathrm{P} 3 \mathrm{a}$ evident. Unfortunately, this study could not distinguish among changes resulting from continued practice, the simple passage of time, and posttraining sleep.

Combining the results of the two studies resolves this question. The current study demonstrates that the slow increase in MMN and appearance of the subsequent $\mathrm{P} 3 \mathrm{a}$ 
Table 1. Training-Induced Changes in the ERPs

\begin{tabular}{|c|c|c|c|}
\hline & $S P W$ & $M M N$ & $P 3 a$ \\
\hline $\begin{array}{l}\text { Maximum peak from start } \\
\text { of standard pattern (msec) }\end{array}$ & 220 & 425 & 525 \\
\hline $\begin{array}{l}\text { Maximum peak from start } \\
\text { of deviant tone (msec) }\end{array}$ & - & 200 & 300 \\
\hline $\begin{array}{l}\text { Seen with standard } \\
\text { sound patterns }\end{array}$ & yes & no & no \\
\hline $\begin{array}{l}\text { Seen with deviant } \\
\text { sound patterns }\end{array}$ & yes & yes & yes \\
\hline $\begin{array}{l}\text { First appearance } \\
\text { (hr after training) }\end{array}$ & 48 & 0 & 48 \\
\hline $\begin{array}{l}\text { Increase in amplitude } \\
\text { (hr after training) }\end{array}$ & - & $48(72 ?)$ & $(72 ?)$ \\
\hline Appearance: sleep-dependent? & no & no & yes \\
\hline Enhancement: sleep-dependent? & - & yes & - \\
\hline
\end{tabular}

is not rehearsal-dependent, since they appeared at $48 \mathrm{hr}$ without intervening rehearsal. In addition, these ERP changes are sleep-dependent, since no such enhancement developed in the sleep-deprived group of the current study. Finally, the changes are time-dependent as well, since the previous study (Atienza et al., 2002a) showed no changes at either 12 or $24 \mathrm{hr}$ (after one night of sleep), but only after 36-48 hr.

The MMN amplitude has been demonstrated to be a robust objective measure of sound discrimination accuracy (Tiitinen, May, Reinikainen, \& Näätänen, 1994). For instance, results from other studies, using the same sound patterns as in the present experiment, indicate that subjects who learn to discriminate between the two patterns show a progressive enhancement of the MMN across the training session (Näätänen et al., 1993) and in subsequent REM sleep (Atienza \& Cantero, 2001), while neither effect is seen in subjects who fail to learn the task. In the present study, however, performance was uncoupled from MMN amplitude, with increases in performance seen both with and without accompanying increases in MMN amplitude. These findings suggest that the slower MMN changes, concentrated at frontal rather than mastoid electrodes and appearing in concert with the P3a, do not contribute directly to task performance. Furthermore, the MMN latency in the control group at 48 and $72 \mathrm{hr}$ did not show the typical shortening in parallel with improvement in performance observed in previous studies (Näätänen et al., 1993). This lack of slow changes in MMN latency further supports the notion that the observed sleep-dependent enhancement of the MMN is not related to the slow improvement in performance.

We propose that the more slowly developing increase in the MMN and P3a serves a more subtle function-the ability of subjects to consciously identify the deviant pattern as a change in the regular sequence in the absence of focused attention, through activation of a frontally triggered automatic shift in attention. In fact, during ERP measurements, subjects were not required to respond or even pay attention to the auditory patterns and were instead reading a book and being instructed to ignore the tones. Thus, before this slowly developing MMN increase was evident, at the end of training for all subjects and even at $48 \mathrm{hr}$ for the sleepdeprived group, subjects would not be aware of the deviant patterns when their attention was focused elsewhere, although they could readily identify them during attentive behavioral testing.

The involvement of MMN and P3a components in different steps of involuntary attention mechanisms, both the generation of a call for attention (the frontal MMN component) and the actual switch of attention (P3a), is supported by different lines of evidence. The strongest support comes from studies involving two simultaneous tasks. In the primary task (in any sensory modality), subjects attend and respond to stimuli; for the secondary (auditory) task, subjects simply ignore auditory stimuli. In this paradigm, stimuli of the primary task are within the focus of attention while sounds of the secondary task are gated out of the attentional focus. Such studies showed increased error rates and prolonged RTs when the attended stimulus in the primary task was preceded by infrequent task-irrelevant sounds (Gaeta, Friedman, Ritter, \& Cheng, 2001; Yago, Escera, Alho, \& Giard, 2001; Escera, Alho, Winkler, \& Näätäenen, 1998; Schröger \& Wolff, 1998; Alho et al., 1997; Schröger, 1996). Impairment in performance was significantly more remarkable when the task-irrelevant stimuli were natural sounds. Additionally, the amplitude of the MMN and P3a was larger for novel (i.e., natural sounds) than deviant sounds (i.e., changes in physical sound features). These results suggest an enhanced switch of attention to stimuli with a greater degree of novelty and salience, and support the role of the MMN and $\mathrm{P} 3 \mathrm{a}$ in triggering and eliciting attentional capture, respectively. Based on our results, this two-step attentional process is enhanced after one night of sleep.

\section{Slow Positive Wave}

In contrast to the MMN and $\mathrm{P} 3 \mathrm{a}$, which peak 200300 msec after the start of the deviant tone and only in response to the deviant sound pattern, the SPW peaks $220 \mathrm{msec}$ after the onset of the sound, prior to the potentially deviant sixth tone, and in response to both standard and deviant patterns. Like the P3a, the SPW only appears $48 \mathrm{hr}$ after training, but, unlike the $\mathrm{P} 3 \mathrm{a}$, it is not sleep-dependent. Interestingly, an SPW-like wave can also be seen in a study of a visual perceptual task under long-term training conditions but not under short-term conditions (Song et al., 2002). Although not noted by the authors, an enhanced long-lasting positive 
wave can be observed immediately following the P2 wave in those subjects who were trained in the discrimination task for three consecutive days, but not those who were only tested on Day 1 (Song et al., 2002: Figure 3, p. 2055). This ERP component showed its maximum at centro-parietal (modality specific) and frontal (modality unspecific) areas in the right hemisphere (personal communication).

Whereas the functional significance of the SPW remains uncertain, it might reflect a change in the cortical organization of the sound. The nature of this change is suggested by subjective reports of a shift in conscious perception of the pattern. While subjects initially reported that they heard the stimulus as a mixed sequence of tones, by the end of training they consistently reported distinguishing a small number of low-frequency tones (three tones at 500-650 Hz) from a background of higher tones (five tones at $720-1170 \mathrm{~Hz}$ ). Such a shift in brain processing would facilitate the task goal of identifying the rare low-frequency tone $(650 \mathrm{~Hz})$ in the spectro-temporal pattern. If the SPW, rather than the MMN and P3a, were responsible for the slow improvement in task performance, it would explain why the control and sleepdeprived subjects showed almost identical behavioral improvement over time. However, if this were the case, the P3a should have been also evident at 48 and $72 \mathrm{hr}$ in the sleep-deprived group, but it did not.

Alternatively, the slow development of the SPW might signal a general increase in familiarity with the sound patterns. The increased positivity linked to the deviant sound would then result from a less intensive processing of the stimulus in auditory cortex. Such an interpretation is supported by studies of rat auditory association cortex, in which Wan et al. (2001) used Fos staining to demonstrate greater neuronal activation following novel rather than familiar complex sound stimuli. In addition, several studies have shown that ERPs become more positive when they are elicited by familiar rather than unfamiliar stimuli. In the "old/new effect," ERPs are more positive starting at about $300 \mathrm{msec}$ when elicited by previously studied (old) compared to nonstudied (new) stimuli (reviewed by Rugg, 1995). On the other hand, the SPW reported here arises earlier $(220 \mathrm{msec}$ from the stimulus onset) and is only seen hours to days later. Thus, off-line mechanisms may be required for these complex patterns to become more familiar.

As in the case of the MMN and P3a, the SPW showed a larger amplitude in the right than in the left hemisphere (see Figures 3 and 4). This is in agreement with results from magnetoencephalographic studies showing that the right hemisphere is predominant in the perception of nonspeech stimuli with slow acoustic transitions (Shtyrov, Kujala, Palva, Ilmoniemi, \& Näätänen, 2000). In that study, the magnetic counterpart of the MMN response was significantly larger in the right hemisphere only for complex-slow stimuli but not for complex-fast stimuli or consonant-vowel stimuli. If the complex-slow sound patterns used in the present study are mainly processed in the right hemisphere, this could also explain the right dominance for the SPW. Likewise, the P3a component in the chimpanzee has shown right lateralization in response to adaptively significant (conspecific) vocal stimuli, whereas no significant laterality was observed with the deviant stimulus in an oddball paradigm (Berntson, Boysen, \& Torello, 1993). Most likely, the right frontal P3a elicited by the deviant sound pattern in our control group signals recognition of the enhanced significance of the stimulus eliciting the shift of attention.

In summary, training on an auditory discrimination task involving complex auditory patterns initiates a series of changes in the cortical dynamics underlying processing of auditory stimuli that continues to develop for at least $72 \mathrm{hr}$ after the completion of training. These changes can be seen directly in ERP modulations and indirectly in improved behavioral performance. Both performance and ERP enhancements can be observed immediately following training, with the appearance of the MMN wave signaling an enhancement of automatic change-detection sensitivity in auditory cortex. More slowly appearing ERP changes fall into two categories that differ in at least three distinctive ways. Variations in the MMN/P3a are dependent on posttraining sleep, are only produced in response to deviant auditory patterns, and have been extensively demonstrated to reflect processes mediating automatic shifts of attention toward new stimuli in the sensory environment when attention is focused elsewhere. In contrast, the SPW is independent of posttraining sleep, is produced by both standard and deviant stimuli and is proposed to reflect processing of familiar stimuli.

While the current study does not provide conclusive evidence, it is tantalizing to suggest that the sleep-dependent processes identified here facilitate a mechanism that triggers the automatic, stimulus-induced shift of attention toward deviations in a learned sound pattern. In this particular case, sleep appears not to enhance the sensitivity of the deviation-detector system while attention is focused on the task. Instead, we suggest, it does so when attention is focused elsewhere. As such, it would act to alert the brain's attentional mechanisms as well as the conscious mind to the presence of meaningful stimuli within the environment. Whether this would be part of a larger brain strategy that uses sleep-dependent processes to identify meaning in the events that make up an organism's life remains to be seen.

\section{METHODS}

\section{Participants}

Twenty university students (13 women, all nonmusicians) gave written consent to voluntarily participate in this study. Medical illness, psychiatric/psychological 
disturbance, substance abuse, and/or neurological disorders were criteria for exclusion.

\section{Stimuli}

Two auditory patterns, $365 \mathrm{msec}$ in duration, were presented binaurally via air tube earphones (Etimotic Research, Model ER-3A) at an intensity of $70 \mathrm{~dB}$ SPL. The standard pattern (87\% of stimuli) consisted of eight 50 msec tones, including overlapped rise and fall times of 5 msec. The eight sequential tones in the standard pattern had frequencies of $720,500,638,1040,1170,565,815$, and $920 \mathrm{~Hz}$. The deviant pattern (13\% of stimuli) differed only in the sixth tone that had a frequency of $650 \mathrm{~Hz}$ (approximately one whole step higher than in the standard sequence). A total of 240 stimuli (36 deviant) were pseudorandomly (2 deviant patterns were always separated by at least two standard patterns) presented in each block with interstimulus intervals of $800 \mathrm{msec}$.

\section{Procedure}

Subjects were trained in a single session for $45-90 \mathrm{~min}$ to respond to the deviant pattern by pressing a key "as accurately and quickly as possible." Training began at 10:30 a.m. or 12:30 p.m., and subjects were retested at the same time of day as they were trained. Start times were balanced across groups. Every subject was presented with a minimum of six 240-stimulus blocks, but the total number of blocks varied between 6 and 13, depending on how quickly subjects reached the learning criteria of $80 \%$ successful detections in each of two consecutive blocks, with a maximum of three false alarms per block. After each block, subjects were required to describe how they perceived the auditory patterns, reproducing vocally the previously heard patterns. Subject performance was subsequently retested with a single stimulus block, 48 and $72 \mathrm{hr}$ after training.

ERPs to auditory patterns were always recorded while subjects read books of their own choosing; subjects were instructed to ignore the stimuli. ERPs were recorded during eight stimulus blocks immediately before and after training, as well as at 48 and $72 \mathrm{hr}$. The latter two recordings were made just prior to performance testing. Subjects completed the Stanford Sleepiness Scale at the beginning and middle (i.e., after four blocks) of each ERP recording session. No significant change in sleepiness was found between groups or across sessions, and thus differences between the two groups cannot be explained by changes in alertness. Since all electrophysiological and behavioral measures were carried out at the same time of day in both groups, circadian effects can also be ruled out as an explanation for betweengroup or between-session differences.

All subjects followed the same protocol except that the 10 experimental subjects were deprived of sleep the night after training. Sleep-deprived subjects slept in the sleep lab (without electrodes) the two following nights to control their sleep schedule. Control subjects slept at home, and recorded their sleep patterns in sleep logs. The two groups reported similar amounts of sleep (controls: $8.00 \pm 0.24 \mathrm{hr}$; sleep-deprived: $7.57 \pm$ $0.29 \mathrm{hr}, p>.2)$.

\section{EEG Recordings}

Electroencephalographic (EEG) activity was recorded in an acoustically shielded room from three $\mathrm{Ag} / \mathrm{AgCl}$ scalp electrodes placed along the midline $(\mathrm{Fz}, \mathrm{Cz}, \mathrm{Pz})$ and six located on the two hemispheres. Pairs of lateral electrodes were referred to as L1/R1 (one-third of the distance from $\mathrm{Fz}$ to each mastoid), L2/R2 (two-thirds of the distance from $\mathrm{Fz}$ to each mastoid), and L3/R3 (mastoids). A reference electrode was placed on the tip of the nose. Vertical eye movements were recorded with electrodes placed above and below the left eye, and horizontal eye movements with electrodes placed $1 \mathrm{~cm}$ lateral to the outer canthus of each eye. Signals were amplified and digitized using a MEDICID 4 system (Neuronic) at $250 \mathrm{~Hz}$ and low- and high-bandpass filtered at 0.1 and $40 \mathrm{~Hz}(-3 \mathrm{~dB}$ frequencies for a $24-\mathrm{dB} /$ octave roll-off curve). Impedance for all electrodes was below $5000 \Omega$.

\section{Analysis of Behavioral Data}

Two measures of performance were obtained: (i) an index of detection sensitivity ( $d^{\prime}$ index) based on the hit rate and false alarm rate and (ii) RT. The $d^{\prime}$ index (Green \& Swets, 1988) was computed by subtracting the $z$ scores for the hit rate $(\mathrm{H})$ from the $z$ scores for the false alarm rate (FA).

$$
d^{\prime}=z_{(\mathrm{FA})}-z_{(\mathrm{H})}
$$

Differences in the $d^{\prime}$ index and in RT, obtained in the last two blocks of the training session and in the remaining retest sessions, were assessed using two separate one-way ANOVA with repeated measures.

\section{Analysis of EEG Data}

For signal averaging, the first five trials of each stimulus block and the trial immediately following each deviant pattern were excluded, as were trials with artifacts exceeding $\pm 100 \mu \mathrm{V}$. For each artifact-free trial, an epoch of $800 \mathrm{msec}$, including a 100-msec prestimulus baseline, was selected. Before averaging, signals were digitally filtered with a cutoff frequency of $30 \mathrm{~Hz}(-3 \mathrm{~dB})$ and drift artifacts corrected using linear detrending. For each subject, ERP averages were computed for the standard and deviant stimulus patterns in each experimental phase (pretraining, posttraining, $48 \mathrm{hr}$ posttraining, 
and $72 \mathrm{hr}$ posttraining). Grand averages were then computed for the control and sleep-deprived groups for each stimulus pattern and experimental session.

The amplitude and latency of the MMN and $\mathrm{P} 3 \mathrm{a}$ components were measured in the difference wave obtained by subtracting the ERP to the standard pattern from that elicited by the deviant pattern. Their latencies were measured as the point where they reached their maximum within $125-200$ and $250-350 \mathrm{msec}$ from the onset of the sixth deviant tone for the MMN and P3a, respectively. Their amplitudes were calculated as the mean value within the $40-\mathrm{msec}$ interval around this maximum. Differences in the latency and amplitude between sessions were compared with two-way ANOVAs, with session as a within factor and group (control or sleep-deprived) as between factor. The degrees of freedom for the within factor (pretraining, posttraining, $48 \mathrm{hr}$ posttraining, and $72 \mathrm{hr}$ posttraining) were corrected with the Greenhouse-Geisser factor. When the within factor was significant, the Newman-Keuls post hoc test was used; otherwise, the $t$ test was applied. The same ANOVA and post hoc tests were computed with the amplitude values of the long-lasting positive wave (SPW) for every $20 \mathrm{msec}$ between 160 and $300 \mathrm{msec}$ from stimulus onset.

\section{Acknowledgments}

We thank M. Walker, E. Pace-Schott, R. Fosse, and A. Muzur for helpful comments on an earlier version of this manuscript and E. Dominguez-Marin and R.M. Salas for assistance in data recordings. This research was supported by NIH grants DA11744 and $\mathrm{MH}-48832$ and by fellowships to M.A. and J.L.C. from the NATO Scientific Program and the Spanish Ministry of Education, respectively.

Reprint requests should be sent to Mercedes Atienza, Centro Andaluz de Biología y Desarollo, Universidad Pablo de Olavide, Carretera de Utrera Km. 1, 41013 Seville, Spain, or via e-mail: matirui@dex.upo.es.

\section{REFERENCES}

Alain, C., Woods, D. L., \& Knight, R. T. (1998). A distributed cortical network for auditory sensory memory in humans. Brain Research, 812, 23-37.

Alho, K., Escera, C., Díaz, R., Yago, E., \& Serra, J. M. (1997). Effects of involuntary auditory attention on visual task performance and brain activity. NeuroReport, 8, 3233-3237.

Atienza, M., \& Cantero, J. L. (2001). Complex sound processing during human REM sleep by recovering information from long-term memory as revealed by the mismatch negativity (MMN). Brain Research, 901, 151-160.

Atienza, M., Cantero, J. L., \& Dominguez-Marin, E. (2002a). The time course of neural changes underlying auditory perceptual learning. Learning \& Memory, 9, 138-150.

Atienza, M., Cantero, J. L., \& Dominguez-Marin, E. (2002a). Mismatch negativity (MMN): An objective measure of sensory memory and long-lasting memories during sleep. International Journal of Psychophysiology, 46, 215-216.

Atienza, M., Cantero, J. L., \& Escera, C. (2001). Auditory information processing during human sleep as revealed by event-related brain potentials. Clinical Neurophysiology, 112, 2031-2045.

Atienza, M., Cantero, J. L., \& Gómez, C. (1997). The mismatch negativity component reveals the sensory memory during REM sleep in humans. Neuroscience Letters, 237, 21-24.

Atienza, M., Cantero, J. L., \& Gómez, C. (2000). Decay time of the auditory sensory memory trace during wakefulness and REM sleep. Psychophysiology, 37, 485-493.

Baudena, P., Halgren, E., Heit, G., \& Clarke, J. M. (1995). Intracerebral potentials to rare target and distractor auditory and visual stimuli. III. Frontal cortex. Electroencephalography and Clinical Neurophysiology, 94, 251-264.

Berntson, G. G., Boysen, S. T., \& Torello, M. W. (1993). Vocal perception: Brain event-related potentials in a chimpanzee. Developmental Psychobiology, 26, 305-319.

Crist, R. E., Li, W., \& Gilbert, C. D. (2001). Learning to see: Experience and attention in primary visual cortex. Nature Neuroscience, 4, 519-525.

Escera, C., Alho, K., Schröger, E., \& Winkler, I. (2000). Involuntary attention and distractibility as evaluated with event-related brain potentials. Audiology and Neurootology, 5, 151-166.

Escera, C., Alho, K., Winkler, I., \& Näätänen, R. (1998). Neural mechanisms of involuntary attention to acoustic novelty and change. Journal of Cognitive Neuroscience, 10, 590-604.

Escera, C., Yago, E., \& Alho, K. (2001). Electrical responses reveal the temporal dynamics of brain events during involuntary attention switching. European Journal of Neuroscience, 14, 877-883.

Fenn, K. M., Nussbaum, H. C., \& Margoliash, D. (2003). Consolidation during sleep of perceptual learning of spoken language. Nature, 425, 614-616.

Fischer, S., Hallschmid, M., Elsner, A. L., \& Born, J. (2002). Sleep forms memory for finger skills. Proceedings of the National Academy of Sciences, U.S.A., 99, 11987-11991.

Gaeta, H., Friedman, D., Ritter, W., \& Cheng, J. (2001). An event-related potential evaluation of involuntary attentional shifts in young and older adults. Psychology and Aging, 16, 55-68.

Gais, S., Plihal, W., Wagner, U., \& Born, J. (2000). Early sleep triggers memory for early visual discrimination skills. Nature Neuroscience, 3, 1335-1339.

Gilbert, C. D. (1994). Learning. Neuronal dynamics and perceptual learning. Current Biology, 4, 627-629.

Gilbert, C. D., Sigman, M., \& Crist, R. E. (2001). The neural basis of perceptual learning. Neuron, 31, 681-697.

Green, D. M., \& Swets, J. A. (1988). Signal detection theory and psychophysics. Los Altos, CA: Peninsula.

Halgren, E., Baudena, P., Clarke, J. M., Heit, G., Liegeois, C., Chauvel, P., \& Musolino, A. (1995). Intracerebral potentials to rare target and distractor auditory and visual stimuli. I. Superior temporal plane and parietal lobe.

Electroencephalography and Clinical Neurophysiology, 94, 191-220.

Halgren, E., Baudena, P., Clarke, J. M., Heit, G., Marinkovic, K., Devaux, B., Vignal, J. P., \& Biraben, A. (1995). Intracerebral potentials to rare target and distractor auditory and visual stimuli. II. Medial, lateral and posterior temporal lobe. Electroencephalography and Clinical Neurophysiology, 94 , 229-250.

Humphrey, D. R. (1968). Re-analysis of the antidromic cortical response. II. On the contribution of cell discharge and PSPS to the evoked potentials. Electroencephalography and Clinical Neurophysiology, 25, 421-442.

Jacobs, K. M., \& Donoghue, J. P. (1991). Reshaping the cortical motor map by unmasking latent intracortical connections. Science, 251, 944-947.

Kapadia, M. K., Gilbert, C. D., \& Westheimer, G. (1994). A 
quantitative measure for short-term cortical plasticity in human vision. Journal of Neuroscience, 14, 451-457.

Karni, A., Tanne, D., Rubenstein, B. S., Askenasy, J. J. M., \& Sagi, D. (1994). Dependence on REM Sleep of overnight improvement of a perceptual skill. Science, 265, 679-682.

Karni, A., Weisberg, J., Lalonde, F., \& Ungerleider, L. G. (1995). Slow changes in primary and secondary visual cortex associated with perceptual skill learning: An fMRI study. Neuroimage, 3, S543.

King, C., McGee, T., Rubel, E. W., Nicol, T., \& Kraus, N. (1995). Acoustic features and acoustic changes are represented by different central pathways. Hearing Research, 85, 45-52.

Kramer, A. F., Humphrey, D. G., Larish, J. F., Logan, G. D., \& Strayer, D. L. (1994). Aging and inhibition: Beyond a unitary view of inhibitory processing in attention. Psychology and Aging, 9, 491-512.

Kraus, N., McGee, T. J., Carrell, T. D., King, C., Tremblay, K., \& Nicol, T. G. (1995). Central auditory system plasticity associated with speech discrimination training. Journal of Cognitive Neuroscience, 7, 25-32.

Kraus, N., McGee, T. J., Carrell, T. D., Zecker, S. G., Nicol, T. G., \& Koch, D. B. (1996). Auditory neurophysiologic responses and discrimination deficits in children with learning problems. Science, 273, 971-973.

Kropotov, J. D., Alho, K., Näätänen, R., Ponomarev, V. A., Kropotova, O. V., Anichkov, A. D., \& Nechaev, V. B. (2000). Human auditory-cortex mechanisms of preattentive sound discrimination. Neuroscience Letters, 280, 87-90.

Loewy, D. H., Campbell, K. B., \& Bastien, C. (1996). The mismatch negativity to frequency deviant stimuli during natural sleep. Electroencephalography and Clinical Neurophysiology, 98, 493-501.

Maquet, P. (2001). The role of sleep in learning and memory. Science, 294, 1048-1052.

Maquet, P., Laureys, S., Peigneux, P., Fuchs, S., Petiau, C., Phillips, C., Aerts, J., Del Fiore, G., Degueldre, C., Meulemans, T., Luxen, A., Franck, G., Van Der Linden, M., Smith, S., \& Cleeremans, A. (2000). Experience-dependent changes in cerebral activation during human REM sleep. Nature Neuroscience, 3, 831-836.

McDowd, J. M. (1997). Inhibition in attention and aging. Journals of Gerontology. Series B, Psychological Sciences and Social Sciences, 52, P265-P273.

Mednick, S. C., Nakayama, K., Cantero, J. L., Atienza, M., Levin, A. A., Pathak, N., \& Stickgold, R. (2002). The restorative effect of naps on perceptual deterioration. Nature Neuroscience, 5, 677-681.

Menning, H., Roberts, L. E., \& Pantev, C. (2000). Plastic changes in the auditory cortex induced by intensive frequency discrimination training. NeuroReport, 11, 817-822.

Näätänen, R. (1990). The role of attention in auditory information processing as revealed by event-related potentials and other measures of cognitive function. Behavioral Brain Science, 13, 201-288.

Näätänen, R. (1992). Attention and brain function. Hillsdale, NJ: Erlbaum.

Näätänen, R., Schröger, E., Karakas, S., Tervaniemi, M., \& Paavilainen, P. (1993). Development of a memory trace for a complex sound in the human brain. NeuroReport, 4 , 503-506.

Näätänen, R., Tervaniemi, M., Sussman, E., Paavilainen, P., \& Winkler, I. (2001). "Primitive intelligence" in the auditory cortex. Trends in Neuroscience, 24, 283-288.

Näätänen, R., \& Winkler, I. (1999). The concept of auditory stimulus representation in cognitive neuroscience. Psychological Bulletin, 125, 826-859.

Nashida, T., Yabe, H., Sato, Y., Hiruma, T., Sutoh, T., Shinozaki,
N., \& Kaneko, S. (2000). Automatic auditory information processing in sleep. Sleep, 23, 821-828.

Opitz, B., Rinne, T., Mecklinger, A., von Cramon, D. Y., \& Schröger, E. (2002). Differential contribution of frontal and temporal cortices to auditory change detection: fMRI and ERP results. Neuroimage, 15, 167-174.

Pascual-Leone, A., \& Torres, F. (1993). Plasticity of the sensorimotor cortex representation of the reading finger in Braille readers. Brain, 116, 39-52.

Picton, T. W. (1992). The P300 wave of the human event-related potential. Journal of Clinical Neurophysiology, 9, 456-479.

Recanzone, G. H., Merzenich, M. M., Jenkins, W. M., Grajski, K. A., \& Dinse, H. R. (1992). Topographic reorganization of the hand representation in cortical area $3 \mathrm{~b}$ of owl monkeys trained in a frequency-discrimination task. Journal of Neurophysiology, 67, 1031-1056.

Recanzone, G. H., Schreiner, C. E., \& Merzenich, M. M. (1993). Plasticity in the frequency representation of primary auditory cortex following discrimination training in adult owl monkeys. Journal of Neuroscience, 13, 87-103.

Rugg, M. D. (1995). Memory and consciousness: A selective review of issues and data. Neuropsychologia, 33, 1131-1141.

Sams, M., Paavilainen, P., Alho, K., \& Näätänen, R. (1985). Auditory frequency discrimination and event-related potentials. Electroencephalography and Clinical Neurophysiology, 62, 437-448.

Scherg, M., Vajsar, J., \& Picton, T. W. (1989). A source analysis of the late human auditory evoked potentials. Journal of Cognitive Neuroscience, 1, 336-355.

Schröger, E. (1996). A neural mechanism for involuntary attention shifts to changes in auditory stimulation. Journal of Cognitive Neuroscience, 8, 527-539.

Schröger, E., \& Wolff, C. (1998). Behavioral and electrophysiological effects of task-irrelevant sound change: A new distraction paradigm. Cognitive Brain Research, 7, $71-87$.

Shadmehr, R., \& Holcomb, H. H. (1997). Neural correlates of motor memory consolidation. Science, 277, 821-825.

Shtyrov, Y., Kujala, T., Palva, S., Ilmoniemi, R. J., \& Näätänen, R. (2000). Discrimination of speech and of complex nonspeech sounds of different temporal structure in the left and right cerebral hemispheres. Neuroimage, 12, 657-663.

Smith, C., \& MacNeill, C. (1994). Impaired motor memory for a pursuit rotor task following Stage 2 sleep loss in college students. Journal of Sleep Research, 3, 206-213.

Song, Y., Ding, Y., Fan, S., \& Chen, L. (2002). An event-related potential study on visual perceptual learning under short-term and long-term training conditions. NeuroReport, 13, 2053-2057.

Stickgold, R., Hobson, J. A., Fosse, R., \& Fosse, M. (2001). Sleep, learning and dreams: Off-line memory reprocessing. Science, 294, 1052-1057.

Stickgold, R., James, L., \& Hobson, J. A. (2000). Visual discrimination learning requires post-training sleep. Nature Neuroscience, 2, 1237-1238.

Stickgold, R., Whidbee, D., Schirmer, B., Patel, V., \& Hobson, J. A. (2000). Visual discrimination task improvement: A multi-step process occurring during sleep. Journal of Cognitive Neuroscience, 12, 246-254.

Tervaniemi, M., Rytkönen, M., Schröger, E., Ilmoniemi, R. J., \& Näätänen, R. (2001). Superior formation of cortical memory traces for melodic patterns in musicians. Learning $\varepsilon$ Memory, 8, 295-300.

Tiitinen, H., May, P., Reinikainen, K., \& Näätänen, R. (1994). Attentive novelty detection in humans is governed by pre-attentive sensory memory. Nature, 372, 90-92. 
Tremblay, K., Kraus, N., \& McGee, T. (1998). The time course of auditory perceptual learning: Neurophysiological changes during speech-sound training. NeuroReport, 9, 3557-3560.

Tremblay, K., Kraus, N., McGee, T., Ponton, C., \& Otis, B. (2001). Central auditory plasticity: Changes in the N1-P2 complex after speech-sound training. Ear \& Hearing, 22, 79-90.

Vaina, L. M., Belliveau, J. W., des Roziers, E. B., \& Zeffiro, T. A. (1998). Neural systems underlying learning and representation of global motion. Proceedings of the National Academy of Sciences, U.S.A., 95, 12657-12662.

Walker, M. P., Brakefield, T., Hobson, J. A., \& Stickgold, R.
(2003). Dissociable stages of human memory consolidation and reconsolidation. Nature, 425, 616-620.

Walker, M., Brakefield, T., Morgan, A., Hobson, J. A., \& Stickgold, R. (2002). Practice with sleep makes perfect: Sleep dependent motor skill learning. Neuron, 35, 205-211.

Wan, H., Warburton, E. C., Kusmierek, P., Aggleton, J. P., Kowalska, D. M., \& Brown, M. W. (2001). Fos imaging reveals differential neuronal activation of areas of rat temporal cortex by novel and familiar sounds. European Journal of Neuroscience, 14, 118-124.

Yago, E., Escera, C., Alho, K., Giard, M. H. (2001). Cerebral mechanisms underlying orienting of attention towards auditory frequency changes. NeuroReport, 12, 2583-2587. 